\title{
¿MINERÍA SUSTENTABLE EN ARGENTINA? CASO: PROYECTO POTASIO RÍO COLORADO ${ }^{1}$
}

\author{
María Ayelén Hollmann* \\ Magalí Villalba**
}

Resumen. Debido al crecimiento de la demanda asiática y de su producción, Latinoamérica vive un auge por la demanda de commodities lo que ha provocado el aumento de las exportaciones de estos bienes. En el caso argentino, el sector metalífero exhibió un importante desarrollo en los últimos años. Mientras las mineras aprovechan este boom, los gobiernos dependen cada vez más de la inversión extranjera para la extracción de estos recursos, así como de los ingresos producto de su renta. En este marco de neoextractivismo, el proyecto Potasio Río Colorado (PRC), desarrollado por la compañía Vale, representaba el mayor emprendimiento minero del país y el más importante de su tipo de Sudamérica. Presupuestado en USD 6.300.000, sólo se ejecutó un $30 \%$ y desde 2013 la obra está paralizada. No obstante, en 2016 Vale retoma el estudio de factibilidad para plantear una reestructuración del diseño original a un tercio de su capacidad y volver el plan atractivo a nuevos socios. Este artículo analiza PRC: orígenes, historia, antecedentes, conflictos de intereses y perspectivas en torno a su potencial reactivación para aportar a una discusión seria e informada sobre el tema. Particularmente, se investiga su sustentabilidad económica, social y medioambiental.

Palabras Clave: Recursos naturales no renovables; Responsabilidad Social Empresaria; Neoextractivismo.

\footnotetext{
* Universidad Nacional del Comahue (UNCo), Argentina

Contacto: ayelenhollmann@gmail.com

** Universidad Nacional del Comahue (UNCo), Argentina

Contacto: magalivillalba@yahoo.com.ar
}

1 Este artículo se enmarca en el proyecto de investigación 04/E109 "El Desarrollo Territorial de la Nord Patagonia y sus escenarios futuros" de la Universidad Nacional del Comahue. Una versión anterior fue presentada en las VIII Jornadas de Economía Ecológica, Rosario, Argentina. 


\title{
SUSTAINABLE MINING IN ARGENTINA? \\ CASE: POTASIO RÍO COLORADO PROJECT
}

\begin{abstract}
Due to the growth of Asian demand and production, Latin America is experiencing a boom in demand for commodities, which has led to an increase in exports of these goods. Argentina does not escape this context, in the case of minerals the activity exhibited an important development in the last years. While mining companies take advantage of this boom, governments are increasingly dependent on foreign investment for the extraction of these resources, as well as incomes from the activity. In this context of neo-extractivism, the Rio Colorado Potassium Project (PRC), developed by Vale, represented the largest mining enterprise in the country and the most important of its kind in South America. Budgeted at USD 6.3 billion, only $30 \%$ was executed, and since 2013 the work is paralyzed. However, in 2016, Vale takes up the feasibility study to propose a restructuring of the original design to a third of its capacity and make the plan attractive to new partners. This article analyzes PRC: origins, history, antecedents, conflicts of interest and perspectives around its potential reactivation to contribute to a serious and informed discussion on the subject. In particular, its economic, social and environmental sustainability is investigated.
\end{abstract}

Keywords: Non-renewable natural resources; Corporate Social Responsibility; Neoextractivism.

Original recibido el 07/12/2017

Aceptado para su publicación el 14/09/2018 


\section{Introducción}

En torno a la actividad minera giran ciertos mitos que muchas veces tergiversan la realidad y la certera capacidad de esta actividad productiva de contribuir a alcanzar el desarrollo deseado. En esta línea, es importante mencionar dos posturas dispares ampliamente difundidas sobre la actividad minera, con el objeto de tender a identificar los beneficios y perjuicios que puedan surgir de su impulso.

El primer mito es aquel que se resguarda en el hecho que la minería es perjudicial en todos sus sentidos y formas, basados en una visión extrema. Los partidarios a esta posición no reconocen el hecho que esta actividad ha acompañado la vida del las personas desde los principios de la historia, y, que en ciertos sentidos, ha sido crucial para el desarrollo de la civilización. Para brindar una respuesta esclarecedora a este mito común, es importante identificar el verdadero rechazo social que genera. Los motivos de la oposición social a los emprendimientos mineros se fundan especialmente en las características económicas y tecnológicas de los mismos. Identificar qué tipo de minería es la que genera rechazo y alta conflictividad social permite visualizar los motivos de la resistencia y pensar en técnicas alternativas de explotación. Básicamente, la minería transnacional a gran escala o megaminería, del tipo "a cielo abierto" es la que genera el mayor rechazo social (Colectivo Voces de Alerta, 2011).

Esta modalidad de minería se generalizó en Argentina con las reformas de la década de los noventa. La característica de explotación de la minería a cielo abierto, cuyas técnicas de procesamiento son la lixiviación o flotación, es la utilización de explosivos para la voladura de montañas con el objeto de generar escalones que dan lugar al "tajo abierto". Estas prácticas producen marcados deterioros en el ambiente y en las localidades próximas a los sitios de explotación. La diferencia fundamental entre la minería "moderna" y la "tradicional" radica básicamente en el tipo de explotación, al pasar de una minería de socavones para obtener metales en veta de alta ley, a una de explotación a cielo abierto en la búsqueda de minerales diseminados, debido al agotamiento de los minerales concentrados.

Un segundo mito, en contraposición al anterior y de carácter netamente optimista hacia la actividad minera, es que la misma es un "motor de desarrollo" que impulsa el crecimiento económico. Estas aseveraciones se fundamentan mediante el discurso de que los grandes montos financieros destinados a la inversión minera y los altos valores de exportación que generan son portadores del desarrollo.

Esta justificación se traduce en mito ya que según la bibliografía consultada, los impactos de la megaminería a gran escala generan extranjerización, concentración y reprimarización de la estructura productiva ${ }^{2}$. Asimismo, se reconoce que el impacto de la actividad minera en las tasas de empleo no es relevante. En las fases iniciales de los proyectos mineros, la demanda de puestos de trabajo es intensiva creando la ilusión de trabajo permanente. De cada USD 1 millón invertidos se crean sólo entre 0,5 y 2 empleos directos (Colectivo Voces de Alerta, 2011).

En este marco y en el contexto argentino en particular, la megaminería es cada

2 Los países donde se radican las fases extractivas se denominan como "economías de enclave". 
vez más cuestionada por distintos sectores de la sociedad (Aranda, 2015), lo que contribuye a un debate sobre este tipo de industria, su normativa y los controles a partir de los cuales puede o no ser posible el desenvolvimiento sustentable de este sector productivo.

\subsection{Planteo del problema y objetivos}

El crecimiento exponencial de la demanda asiática y al aumento de su producción tuvo numerosos efectos a nivel mundial. Sin dudas, para Latinoamérica significo, entre otras cosas, una mayor demanda de commodities lo que derivó en un aumento de las exportaciones de estos bienes. Argentina no escapa a este contexto y un caso a analizar es el del sector metalífero. Este sector exhibió un creciente desarrollo en los últimos años donde se observa un repunte de los precios internacionales (KPMG, 2018).

Teniendo como principal objetivo la maximización de ganancias, las empresas multinacionales que realizan estas explotaciones han ampliado la frontera extractiva hacia nuevos territorios donde aún existe gran cantidad de reservas naturales sin explotar, llevando a las comunidades locales a conflictos sociales por sus derechos territoriales (Veltmeyer y Petras, 2015).

Mientras las compañías mineras aprovechan el boom de los commodities para aumentar su acumulación de capital, los gobiernos dependen cada vez más de la inversión extranjera para la extracción de los recursos naturales de sus suelos, así como de los ingresos públicos producto de las rentas derivadas de esa actividad. Al mismo tiempo, este tipo de industrias de extracción primaria representa uno de los casos más difíciles para la interpretación de la sustentabilidad ya que involucran el manejo de recursos naturales no renovables e impactos en el ambiente producto de la extracción de los minerales, su procesamiento y utilización.

El debate por la sustentabilidad de la industria minera no solo es un debate que incumbe al recurso extraído en sí, sino a toda la actividad en general ya que ésta insume cantidades considerables de agua, energía eléctrica y gas. Esto genera numerosos impactos socioeconómicos en las comunidades locales relacionadas con la actividad. Sin embargo, "a pesar de todos esos debates, y de la creciente evidencia de su limitada contribución a un genuino desarrollo nacional, el extractivismo goza de buena salud" (Gudynas, 2009, p.187).

En este marco neoextractivista, las empresas de capitales transnacionales y concentrados, generan dinámicas de enclave, desarticulando las economías regionales al desplazar comunidades y vaciar territorios, utilizando tecnologías que no son intensivas en mano de obra. Se genera un aumento de la conflictividad social ante la expansión de estos emprendimientos que buscan verticalmente imponer sus lógicas entre las comunidades a base de ocupación territorial sin consultas a las poblaciones locales (Svampa, 2016; Svampa y Viale, 2014).

Este trabajo tiene por objetivo analizar específicamente el Proyecto Potasio Río Colorado (PRC). Se indaga en sus orígenes, historia, antecedentes nacionales e internacionales, normativa vigente del sector, conflictos de intereses surgidos, así como las perspectivas a futuro que se presentan en el país en torno a su 
potencial reactivación y a la megaminería en general. Particularmente, se investiga la responsabilidad social de la empresa en el proyecto identificando si existe sustentabilidad económica, social y medioambiental en la actividad extractiva.

\section{Metodología}

La metodología de investigación utilizada en es cualitativa y de tipo analíticadescriptiva, ya que permite analizar y describir los estados de las diferentes variables que se pretende estudiar y cómo se manifiestan en la práctica teniendo en cuenta el contexto, facilitando la caracterización del fenómeno sujeto a estudio. Para ello, las técnicas de recolección de datos utilizadas fueron variadas. Se analizaron las declaraciones y distintos informes emitidos por las propias empresas mineras a lo largo del proyecto, así como los estudios de impacto ambiental; la legislación vigente a nivel nacional, de las provincias y municipios en relación con el emprendimiento; diferentes documentos, estadísticas y boletines oficiales; actas-acuerdo firmados entre los distintos estados intervinientes y la minera, así como toda aquella bibliografía relacionada al desarrollo de esta investigación.

\section{El proyecto}

El proyecto PRC, que llevaba adelante la minera de capitales brasileños Vale, representaba el mayor emprendimiento minero en la Argentina. Esta iniciativa consistía en la producción, industrialización y distribución de cloruro de potasio para su utilización como fertilizante agropecuario. PRC, originalmente presupuestado en USD 6.300.000, de los cuales se ejecutó un $30 \%$, contemplaba la extracción y el transporte de potasio desde Mendoza a Brasil, con la construcción de una mina, un tendido ferroviario e instalaciones portuarias en la localidad de Ingeniero White, a $10 \mathrm{~km}$ de la ciudad de Bahía Blanca. Las instalaciones portuarias contarían con el correspondiente acceso ferroviario, una planta de compactación e instalaciones de almacenamiento.

\subsection{Ubicación}

El yacimiento se ubica en el extremo sur de la provincia de Mendoza, próximo al Río Colorado y a la localidad Pata Mora en el departamento de Malargüe (Imagen 1). De acuerdo con el proyecto original, el transporte del cloruro de potasio se realizaría por ferrocarril a través de una vía férrea de $870 \mathrm{~km}$ de extensión que uniría el yacimiento con el puerto de Ingeniero White. Para esto, serían construidos $370 \mathrm{~km}$ nuevos desde las cercanías de la localidad de Rincón de los Sauces, provincia del Neuquén, hasta la localidad de Chichinales, provincia de Río Negro, en donde se empalmarían con los preexistentes $500 \mathrm{~km}$ que serían reparados y acondicionados. 
Imagen 1. Imagen satelital del Proyecto Potasio Río Colorado y zonas aledañas

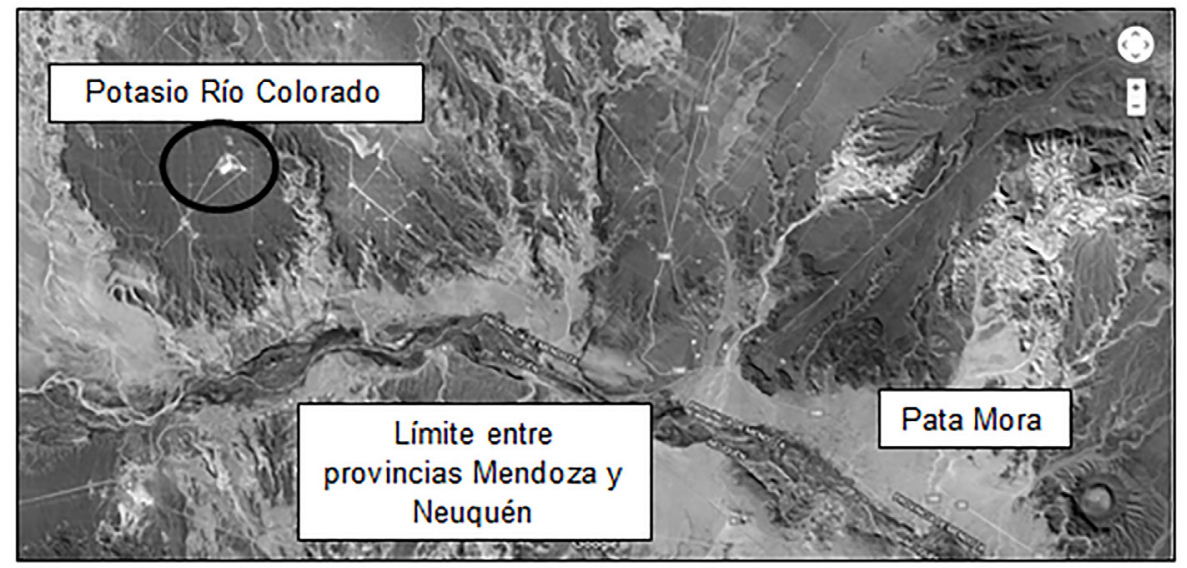

Fuente: Elaboración propia en base a Google Maps.

De este modo, el recorrido ferroviario pasaría por el noreste de la provincia del Neuquén, luego por el norte de la provincia de Río Negro, siguiendo por el sur de la provincia de La Pampa hasta llegar a Bahía Blanca. Este emprendimiento, cuya producción se estimaba en 2,4 millones de toneladas de cloruro de potasio por año, convertiría al país en el sexto productor mundial de este mineral. Toda la producción se exportaría a Brasil, que consume cerca de 7 millones toneladas de potasio por año.

\subsection{Sus inicios}

En la década de los noventa fue una empresa de capitales nacionales, Minera Tea S.A., la que obtiene el permiso del gobierno mendocino para iniciar los estudios tendientes a la explotación del manto de cloruro de potasio y cloruro de sodio situado a aproximadamente 1.000 metros de profundidad, que pasa el territorio mendocino por debajo del Río Colorado y continúa en la provincia del Neuquén. Minera Tea S.A. crea la empresa Potasio Río Colorado S.A. iniciando la etapa de prefactibilidad del proyecto en las cercanías del Río Colorado. El río Colorado es de aguas compartidas por las provincias de Mendoza, Neuquén, Río Negro, La Pampa y Buenos Aires, las cuales conforman el Comité Interjurisdiccional del Río Colorado (COIRCO) encargado de proteger los recursos de la cuenca con un tratamiento interprovincial. En el año 2003 la empresa Río Tinto ${ }^{3}$ suscribe un acuerdo con la firma Minera Tea por el cual obtiene una opción de compra del $100 \%$ de Potasio Río Colorado por un período de dos años durante los cuales la empresa opera el proyecto piloto y finalmente pasa a tener la titularidad de PRC en el 2005 ejerciendo su opción de compra. En 2009, en plena crisis económica internacional, el proyecto minero pasa a manos de la empresa brasilera Vale Do Rio Doce, por USD 850 millones. Vale, segunda empresa minera a nivel mundial, posee operaciones en más de 30

3 Esta empresa tiene distintas causas judiciales alrededor del mundo. Un ejemplo es la acusación por discriminación y crímenes de lesa humanidad contra nativos en Papúa Nueva Guinea. 
países de los cinco continentes, siendo también una de las mayores productoras y exportadoras de hierro. En los últimos años, de la mano del aumento del consumo mundial de alimentos y de la producción agrícola, la empresa ha diversificado su portfolio de productos por medio de una mayor participación en la industria de los fertilizantes. Vale está en la mira de numerosas organizaciones socioambientales, tanto así, que ostenta el galardón a la peor corporación del mundo de acuerdo con el Premio Public Eye que le fuera otorgado en el año 2012, conocido como el "Nobel" de la vergüenza mundial corporativa ${ }^{4}$.

\section{Desarrollo sustentable y Responsabilidad Social Empresaria (RSE)}

A nivel mundial, existe consenso de que la estrategia procedente de la acción privada para alcanzar un modelo basado en el desarrollo sustentable es justamente la RSE. Bajo esta práctica, el desarrollo sustentable es un concepto macroeconómico ya que plantea el reto de combinar una economía dinámica con una sociedad que ofrezca oportunidades para todos/as, al tiempo que se mejora la productividad de los recursos y se desliga el crecimiento de la degradación del medio ambiente (Morrós Ribera y Vidal Martínez, 2005). La responsabilidad social tiene que ver directamente con el desarrollo sustentable y con que las posibilidades de autodesarrollo de las comunidades no se vean limitadas por lo que se define como una actividad, sino por el contrario sean potenciadas por ésta.

Una definición de RSE internacionalmente aceptada es "la responsabilidad de las empresas por su impacto en la sociedad" (Comisión Europea, 2011, p. 7), siendo el respeto y cumplimiento de la legislación aplicable, un requisito previo a la RSE.

Para asumir esa responsabilidad las empresas deben aplicar, en estrecha colaboración con las partes interesadas (grupos de interés), un proceso destinado a integrar las preocupaciones sociales, medioambientales y éticas, el respeto de los derechos humanos y las preocupaciones de los consumidores en sus operaciones empresariales y su estrategia básica, con el doble objetivo de:

- maximizar la creación de valor compartido para sus propietarios/accionistas y para las demás partes interesadas y la sociedad en sentido amplio;

- identificar, prevenir y atenuar sus posibles consecuencias adversas.

"Una consecuencia muy importante de esta noción de responsabilidad, medida por el

4 De acuerdo con las entidades que nominaron a Vale para el Premio Public Eye 2012 (entre ellas la Organización Brasileña Rede Justiça nos Trilhos, las ONGs Amazon Watch e International Rivers y la Alianza Internacional de Habitantes) el hecho de ser Vale una transnacional presente en 38 países y con impactos desperdigados por el mundo amplió el número de votantes. Para los organizadores del premio, la entrada de la empresa a mediados de 2010 en el Consorcio Norte Energía S.A., emprendimiento responsable por la construcción de Belo Monte, fue un factor determinante para su inclusión en la lista de las seis finalistas del Public Eye de ese año.

Este premio fue creado en el año 2000 por Greenpeace Suiza y la Declaración de Berna y se lleva a cabo durante el Foro Económico Mundial, en la ciudad suiza de Davos. Es concedido anualmente a la empresa escogida por voto popular en función de sus problemas ambientales, sociales y laborales. 
impacto objetivo de los comportamientos, es que toda la comunidad se hace, directa o indirectamente, corresponsable" (Licha, 2012, p.13). Es decir, estos impactos se enfrentan con el grado de eficacia de la normativa legal vigente que deben respetar las organizaciones, y ponen a prueba también, los mecanismos de fiscalización y control que todos los grupos de interés (como ser el estado en primer lugar, el tercer sector y la comunidad) han desarrollado para prevenir las potenciales externalidades negativas de las distintas actividades económicas.

Otro aspecto a destacar de la definición citada es que el comportamiento de las organizaciones socialmente responsables se caracteriza por ser el centro de la gestión empresarial básica. Es así que su desarrollo no refiere a circunstancias esporádicas sino que está ligado a la sustentabilidad, es decir, que las acciones del presente son una verdadera apuesta para el futuro (Hollmann, 2015).

\subsection{La Responsabilidad Social Empresaria en la Minería}

La minería actual difiere mucho de aquella de sólo un par de décadas atrás, debido, entre otros aspectos, al incipiente uso de tecnologías denominadas ecoeficientes ${ }^{5}$. A esto se le suma la aparición de nuevas corrientes de gestión corporativa que claman sobre la RSE de las mineras. Sin duda, estos cambios también fueron posibles principalmente por cuatro hechos (Arias Arce, Lovera Dávila, Puente Santibañez y Calderón Celis, 2009): la globalización de la economía y por ende la sensibilización de los estándares sociales; una mayor competencia por capitales de riesgo que hizo que los inversionistas aplicaran buenas prácticas corporativas y estándares más altos; el deterioro ambiental por la mala práctica de la sustentabilidad; y la influencia de las ONGs para la agudización de las diferencias entre empresas mineras y su entorno.

\section{Resultados}

\subsection{Evaluación del Impacto Ambiental}

En 2006 la empresa Río Tinto presenta la solicitud del Informe de impacto ambiental y comienza a realizar los estudios de factibilidad, ambos exigidos por la legislación nacional. La Ley nacional 25675 (Ley General del Ambiente) en su Artículo 8 fija como uno de los instrumentos de la política y la gestión ambiental, la Evaluación de Impacto Ambiental. Específicamente trata el tema en los Artículos 11 y 12 estableciendo que toda obra o actividad que, en el territorio de la Nación, sea susceptible de degradar el ambiente, alguno de sus componentes, o afectar la calidad de vida de la población en forma significativa, estará sujeta a un procedimiento de evaluación de impacto ambiental previo a su ejecución. El Artículo 12 establece que se dará inicio al procedimiento con la presentación de una declaración jurada en la que se manifieste si las obras o actividades afectarán el ambiente y que las autoridades competentes determinarán la presentación de un estudio de impacto ambiental. Por su parte, el Artículo 21 expresa que deberá asegurarse la participación ciudadana en los procedimientos de evaluación de impacto ambiental.

5 El término ecoeficiencia fue acuñado por el World Business Council for Sustainable Development en su publicación del año 1992 Changing Course: A Global Business Perspective On Development And The Environment. Está basado en el concepto de crear más bienes y servicios utilizando menos recursos y creando menos basura. 
A su vez, el Código de Minería argentino establece en su Artículo 251 la obligación de contar con el certificado de impacto ambiental antes de iniciar cualquiera de las etapas que comprende la actividad minera.

En lo que respecta a la legislación mendocina, la Ley provincial 5961 (Ley sobre preservación, conservación, defensa y mejoramiento del ambiente) en su Título V: "Del impacto Ambiental", Artículo 26, establece que se entiende por evaluación de impacto ambiental el procedimiento destinado a identificar e interpretar, así como a prevenir, las consecuencias o efectos que acciones o proyectos puedan causar al equilibrio ecológico, al mantenimiento de la calidad de vida y a la preservación de los recursos naturales existentes en la provincia.

Así también específica en su Artículo 27 que todos los proyectos capaces de modificar el ambiente del territorio provincial, deberán obtener una Declaración de Impacto Ambiental. En su Artículo 29 da las pautas para el procedimiento de evaluación de impacto ambiental ${ }^{6}$. Luego, en su Artículo 31, determina que el Ministerio de Medio Ambiente, Urbanismo y Vivienda o el Municipio correspondiente, deberá convocar a audiencia pública a las personas físicas o jurídicas potencialmente afectadas por el proyecto y a las organizaciones no gubernamentales interesadas en la preservación de los valores ambientales que la ley protege.

Cabe señalar, siguiendo con la legislación vigente, que por no ser este emprendimiento de explotación de minerales mediante la utilización elementos químicos en sus procesos (sino que utiliza agua caliente en los procesos extractivos), quedó fuera del alcance de la Ley mendocina 7722. Esta ley, sancionada en 2007, prohíbe en el territorio de la provincia de Mendoza la explotación a cielo abierto de sustancias químicas.

Como se observa, en la legislación argentina se encomienda al propio interesado en un emprendimiento la realización del estudio de impacto ambiental. Esto podría resultar inconsecuente ya que difícilmente una consultora contratada por los propios interesados se expondría a una situación contraria a sus contratantes y se pueda esperar de ellos una interpretación que le de prioridad al ordenamiento territorial y a la preservación del ambiente, ya que el interés de estas empresas en torno a la localización de las actividades humanas en la zona es primordialmente de tipo económico.

En este marco, el estudio de impacto ambiental del proyecto PRC no alertaba sobre los compromisos que implicaba, por ejemplo, situar en la proximidad del Río Colorado el acopio de sodio ni la acción de los agentes climáticos sobre ese repositorio. La

6 De acuerdo con el Artículo 29, el procedimiento de evaluación de impacto ambiental debe estar integrado por las siguientes etapas:

a) la presentación de la manifestación general de impacto ambiental y, en su caso, la manifestación específica de impacto ambiental;

b) la audiencia pública de los interesados y afectados;

c) el dictamen técnico;

d) la declaración de impacto ambiental. 
región, si bien es semiárida, posee precipitaciones de carácter torrencial y también está sometida a fuertes vientos, además, existe el riesgo de la acción sísmica, todos factores que pueden impactar sobre el riesgo de vertido de la sal en el río. Si su salinidad aumentase, afectaría a todas las zonas de irrigación situadas aguas abajo.

\subsection{Especificaciones técnicas del proceso de producción y extracción utilizado}

El proceso de producción para la extracción de cloruro de potasio, de acuerdo con el resumen ejecutivo del informe de impacto ambiental del Proyecto PRC (2008), se realizaría a través de la llamada minería por disolución, un método de explotación que consiste en bombear agua caliente hacia la zona que contiene al mineral, en este caso a 1.100 metros de profundidad. Allí y con la acción del agua, los minerales son disueltos para luego ser ascendidos hacia la superficie a través de un pozo de recuperación.

Es así que el proyecto elaborado por la minera contemplaba la excavación de dos pozos paralelos hasta llegar al nivel donde se encuentra el manto salino, por uno de los conductos se inyectaría a presión agua a $70^{\circ} \mathrm{C}$ de temperatura y por el otro se extraería la salmuera que contendría una mezcla de ambas sales (cloruro de potasio más cloruro de sodio), en una proporción de 1,1 toneladas de cloruro de sodio por cada tonelada de la sal potásica. Ya en superficie las dos sales serían separadas por diferencia de densidad, el cloruro de sodio se acumularía en un repositorio mientras que la sal potásica se concentraría por evaporación y luego sería transportada al puerto de Bahía Blanca desde donde se exportaría a Brasil.

Con respecto al potasio, es importante señalar que cerca del $95 \%$ del cloruro de potasio producido a nivel mundial se utiliza como fertilizante ya que es uno de los tres principales macronutrientes para las plantas y debe reponérselo regularmente en los suelos agrícolas ${ }^{7}$. Tres países producen dos tercios de este mineral a nivel mundial: Canadá, Rusia y Bielorrusia. El resto es producido por otros nueve países, incluida una pequeña producción en Chile y Brasil. A nivel del consumo, Estados Unidos, China, Brasil e India encabezan la lista. No obstante, ninguno de ellos cuenta con una producción propia de importancia (Gómez y Baudino, 2008). En Argentina, la mayor parte de los suelos de las áreas de cultivo se encuentran provistas de este mineral, por tal razón las fórmulas utilizadas en los fertilizantes en Argentina no contienen potasio. En cambio, los suelos brasileños son deficitarios en este nutriente.

Para la extracción del potasio se requeriría una dotación de agua de $1 \mathrm{~m}^{3} / \mathrm{seg}$, esto es igual a un volumen total diario de 86,4 millones de litros. Esta cantidad es equivalente a la necesidad de abastecimiento en agua de una población de 320 mil habitantes. En este proceso el agua que se utilizaría es la procedente del Río Colorado, ubicado a escasos kilómetros de la planta y que llegaría a través de ductos, no retornando al río.

El calentamiento hasta los $70^{\circ} \mathrm{C}$ de ese enorme volumen de agua consumiría diariamente un millón de $\mathrm{m}^{3}$ de gas, equivalente al consumo diario (domiciliario e industrial) de toda la provincia de Mendoza. Sin embargo, se desconocía de

7 El potasio en las plantas es importante para la regulación osmótica e iónica, juega un papel clave en la homeostasis del agua y se encuentra íntimamente relacionado con los procesos de la síntesis de proteínas. 
dónde provendría el gas necesario y aún restaba la obtención de un permiso de la Secretaría de Energía de la Nación que diera respuesta al suministro energético que demandaría la planta durante su actividad.

Para concluir con el aspecto energético debe agregarse que, además del gas, el emprendimiento requeriría $78 \mathrm{MW}$ por segundo de fluido eléctrico. Nuevamente, para dar una idea aproximada de lo que representan esos $78 \mathrm{MW}$ puede compararse con la utilización total de electricidad por parte de las industrias mendocinas.

El acopio del cloruro de sodio o sal común se realizaría en superficie mediante la construcción de un depósito que abarcaría unas 230 hectáreas aproximadamente. El repositorio de cloruro de sodio, al final de los 35 años de explotación del yacimiento (representa la vida útil calculada), formaría una pila de sal de 210 hectáreas y 50 metros de altura. Para evitar la dispersión de la sal por acción de la lluvia o los vientos, el depósito sería cerrado y el sistema de almacenaje previsto sería a través de celdas en las que se acopiaría la sal, las que serían selladas una vez que se complete su capacidad. Asimismo, la sal estaría aislada del suelo (para evitar filtraciones hacia las capas freáticas) mediante una membrana plástica de la cual sería imposible pronosticar su real duración, sometida como estaría a enormes presiones y a la dureza del clima de la región. Pero este no es el único riesgo, el proyecto de Vale preveía, por una cuestión de costos, emplazar el repositorio en la cercanía del yacimiento, lo que implicaba también una estrecha cercanía al Río Colorado, a unos $18 \mathrm{~km}$.

\subsection{Oposición al proyecto}

La coalición que se oponía al emprendimiento PRC estaba conformada principalmente por la Asamblea Mendocina por el Agua Pura ${ }^{8}$ ligada a asociaciones ambientalistas y a otras organizaciones opuestas al desarrollo de la actividad minera. Del otro lado, se encontraban además de Vale Do Rio Doce, los gobiernos provinciales y el gobierno nacional. Este último en 2008 declaró al proyecto de interés nacional por medio del Decreto 2019/2008. EI COIRCO, por su parte, exigió las garantías necesarias para que el proyecto se realice bajo normas de control y cuidado ambiental, y finalmente en 2009 aprobó el proyecto para administrar el caudal del río necesario.

Quienes se oponían al proyecto sostenían que el pasivo ambiental que dejaría PRC era todavía difícil de pronosticar de acuerdo con el estado de avance de la obra y que el mismo demandaría un consumo excesivo de agua y de energía eléctrica,

8 A fines de 2006 las organizaciones sociales de General Alvear, San Rafael y Valle de Uco realizaron una actividad a la que denominaron "Ayuno y Actividad Cultural" en los alrededores de la legislatura provincial de Mendoza, dado que allí se daría tratamiento a una ley que proponía suspender el otorgamiento de derechos mineros en la provincia hasta tanto no se contara con un plan ambiental. Esta ley, sancionada por la legislatura, fue vetada por el entonces gobernador de la provincia. En respuesta a estos hechos, en diciembre de ese año se organizó la Asamblea Popular por el Agua del Gran Mendoza. La articulación de esta asamblea con los otros grupos existentes dio por resultado la Asamblea Mendocina por Agua Pura (AMPAP). La AMPAP es, desde entonces, un espacio donde los diversos grupos que rechazan la megaminería en Mendoza coordinan sus acciones y planifican estrategias de lucha. Fueron estas asambleas de vecinos autoconvocados y otras organizaciones las que, a mediados de 2007, lograron la sanción de la Ley provincial 7722. 
liberando montañas de sal que quedarían como remanentes del proceso industrial afectando el ecosistema y el desarrollo regional. En el Foro "En defensa del Río Colorado"9 representado por integrantes de distintas provincias, organizaciones de la sociedad civil y organismos públicos, luego de analizar y debatir sobre PRC se llegó a la conclusión que el mismo no respondía a un modelo de Desarrollo Sustentable.

Por su lado, la empresa minera aseguraba tener una solución técnica para este problema y ponía el acento en tres cuestiones básicas: responsabilidad ambiental, desarrollo económico y compromiso social. La aprobación en 2009 de la Declaración de Impacto Ambiental (DIA) emitida por el gobierno de la provincia de Mendoza que autorizaba las etapas de construcción y producción del proyecto Potasio Río Colorado, marcó uno de los puntos de máxima escalada del conflicto.

Sin embargo, los principales damnificados han sido los trabajadores que quedaron desocupados, que si bien tomaron medidas tanto en territorio neuquino como mendocino para hacer escuchar sus necesidades y reclamos por las promesas laborales incumplidas, no recibieron respuesta positiva por parte de Vale.

\section{Discusión}

En 2009, el gobierno de Mendoza a través de la autoridad ambiental que ejerce la Dirección de Protección Ambiental y la Dirección de Minería, otorga a la empresa, ya en ese entonces Vale Do Rio Doce, la Declaración de Impacto Ambiental (DIA) que autoriza las etapas de construcción y producción del proyecto. El Acta Acuerdo de la DIA también contenía el compromiso de la empresa de constituir un fondo de desarrollo socioambiental por USD 12 millones. La DIA fue rechazada por las distintas organizaciones sociales y medioambientales contrarias al emprendimiento por medio de cortes de ruta y la emisión de un comunicado donde manifestaban su preocupación por la autorización del proyecto.

Uno de los temas que más controversia causó en torno al proyecto fue el compromiso del "Compre Mendocino" del acta acuerdo firmada entre la empresa y el gobierno de Mendoza. Primero la empresa fue apercibida por no detallar el origen del personal y proveedores contratados y más tarde fue sancionada con la suspensión del proyecto hasta que se cumpliera lo convenido en el acta acuerdo de la DIA. A estos inconvenientes se sumaron los reclamos de la Unión Obrera de la Construcción de la República Argentina (UOCRA), en apoyo al gobierno por las medidas adoptadas, y varias complicaciones en relación al proyecto ferroviario que intentaba establecerse desde la Provincia del Neuquén hasta la zona portuaria de Bahía Blanca. En agosto de 2011, el gobierno mendocino dio por concluida dicha suspensión, asegurando que la empresa estaba cumpliendo con buena parte de los puntos acordados en el Acta.

El gobierno neuquino también requirió a Vale el "Compre Neuquino" en lo que sería la construcción del ferrocarril, para la priorización en la contratación de mano de obra y de insumos de la provincia, atendiendo a la Ley provincial 2755 que prevé el $75 \%$ de contratación de mano de obra provincial y el $25 \%$ foránea.

9 El Foro fue organizado por el gobierno de la provincia de La Pampa, la Cámara de Diputados de La Pampa, la Cooperativa Popular de Electricidad, la Fundación Chadileuvú, la Universidad Nacional de La Pampa y la Asociación Alihuen. 
Asimismo, el gobierno neuquino siguiendo con su particular forma de gestión de la Responsabilidad Social ${ }^{10}$, realizó un acuerdo con la minera por USD 11 millones en concepto de RSE, mediante Acta Compromiso suscripta en 2011 y ratificada por el Decreto 1519/2011. Allí se estipulaba que las localidades, no la empresa, serían las que determinarían el destino del dinero proveniente en concepto de la RSE de la propia Vale, como parte de la política de desarrollo sustentable bajo la cual desarrollaba PRC.

El Acta Compromiso disponía la creación de un fondo de desarrollo socioambiental a los fines de mejorar la infraestructura provincial y municipal en Rincón de los Sauces y en las comunidades cercanas. A tales efectos, se constituiría un Fondo Fiduciario que sería administrado por dos representantes de la provincia, un representante de Vale y tendría participación también el intendente de Rincón de los Sauces. Los USD 11 millones serían pagaderos en 18 cuotas a partir de que se instalase el campamento para la construcción de los 170 kilómetros de ferrocarril.

Aquí cabe preguntarse si las acciones de RSE de PRC no deberían estar a cargo de la propia empresa en vez de ser digitadas por el Estado y si las obras públicas que se harían en nombre de la RSE de Vale, deberían ser realizadas por el Estado y no por una empresa de la megaminería. Atendiendo a su soberanía, el Estado tendría que sobreponerse a este tipo de acuerdos, desde el momento que es él quien representa los intereses de los ciudadanos, mediante la defensa del patrimonio público, el bien común y la planificación del uso del territorio. En particular cuando se trata del establecimiento de actividades económicas que tienen un alto impacto en el ambiente.

Otro hecho a puntualizar es que el tren surcaría el territorio de la provincia del Neuquén sin existir un estudio previo de impacto ambiental para esa zona, siendo que se calcula que las formaciones ferroviarias para estar relacionadas con el ritmo de extracción de la sal tendrían que transportar cada dieciocho horas cinco mil toneladas del fertilizante, para lo cual deberían utilizarse formaciones de trenes de alrededor de mil metros de extensión. Rincón de los Sauces y sus adyacencias constituyen una de las áreas de explotación petrolera y gasífera más importante del país (representando la principal actividad económica de la zona) y toda la región esta surcada por tuberías que transportan uno u otro fluido. Ante este escenario, la trepidación producida por el paso del tren podría llegar a ocasionar serias consecuencias.

La provincia del Neuquén se encuentra emplazada dentro de la Cuenca Neuquina, la más relevante del país en cuanto a extracción de gas. En la Cuenca Neuquina, al igual que en el resto del país, las actividades en el sector extractivo se desarrollan bajo la modalidad de enclave, que implica que los vínculos económicos con otros sectores son mínimos, la demanda de empleo es escasa y los beneficios son altos, aunque fluyen fuera de la región, de acuerdo a los objetivos de las concesionarias multinacionales. Esta circunstancia se ha profundizado desde la desregulación del sector hidrocarburífero a partir de 1989 (Giuliani, 2013).

$10 \mathrm{El}$ tema es desarrollado en la ponencia "Fondo fiduciario de Administración Responsabilidad Social Empresaria - Ley 2615 Provincia del Neuquén” por Hollmann y Giuliani (2011). 
Siguiendo la política de Mendoza y Neuquén, Río Negro también suscribe con la empresa Vale un acta acuerdo creando un Fondo Fiduciario de desarrollo socioambiental para el cual la empresa se comprometía a realizar un depósito de USD 11 millones destinados a obras públicas.

\subsection{Cese de actividades}

Finalmente, a mediados de 2012, Vale pone en revisión el proyecto. La minera ya había congelado una iniciativa similar en Canadá ${ }^{11}$. La empresa alega que decidió suspender los trabajos "producto de varios efectos y de una situación global" y que debía hacer "una revisión de las variaciones en los fundamentos económicos". Mediante un comunicado, la firma confirmaba la paralización de trabajos argumentando que el aumento de costos comprometía la viabilidad del proyecto. Entre los puntos que destacaba la misiva como los causantes de la pérdida de atractivo del emprendimiento subrayaba "la actuación del gobierno nacional junto a las provincias y municipalidades para reducir o eliminar demandas políticas que encarecen el proyecto".

En 2013 la Corte Suprema de Brasil falló contra la minera Vale y dispuso que la deuda impositiva que debía liquidar al fisco ascendía a USD 14.000 millones. EI tribunal declaró constitucional las normas tributarias para filiales extranjeras, en un litigio que databa desde la década de los noventa, y que la compañía luego utilizó como otro de los motivos de su retiro de Argentina.

La totalidad de los contratos que tenía Vale con las subcontratistas argentinas abarcaban más de 6.000 empleados. Sólo en Mendoza, principalmente en Malargüe, la empresa empleaba en forma directa a más de 400 personas y a otras 4.200 a través de contratistas. En Bahía Blanca, la obra del puerto quedó a medio terminar dejando a 1.100 desocupados pertenecientes a la contratista principal, y otros 300 de las empresas subcontratistas. En Neuquén, el principal impacto se dio en Rincón de los Sauces, donde había cerca de 400 contratados para la obra ferroviaria.

En abril de 2013 se vencía la conciliación obligatoria impuesta a Vale, razón por la cual el Ministerio de Trabajo, Empleo y Seguridad Social de la Nación dictó un procedimiento preventivo de crisis por 30 días más, lo que obligó a contratistas y subcontratistas de PRC a seguir pagando salarios. En la misma época, el Ministerio de Trabajo establece la apertura del procedimiento preventivo de crisis, con el fin de negociar un acuerdo con la empresa, pese a que ésta ya informara su retiro del país. Mediante los acuerdos firmados entre representantes de los distintos sectores, Vale canceló las deudas con los empleados hasta marzo de 2013, estableciéndose que recibirían una gratificación extraordinaria de 5 medios sueldos pagados en cuotas iguales y consecutivas hasta octubre de ese año.

Por otro lado, el gobierno neuquino determinó, mediante Decreto 739/2013, que Vale tenía una deuda de USD 4 millones con la provincia en concepto de RSE ( $40 \%$ del aporte a integrar atento al inicio de obra de construcción del ferrocarril) en el marco del compromiso asumido mediante Acta suscripta en agosto de 2011 y ratificada por 11 En 2012 la minera brasileña congeló en Canadá un proyecto de inversiones por USD 3.000 millones en minas de potasio frente a las dudas que le generaría el actual momento económico mundial. 


\section{Decreto 1519/2011.}

En septiembre de 2016 el Ministerio de Energía, Servicios Públicos y Recursos Naturales de la Provincia del Neuquén informa a Fiduciaria Neuquina S.A. que, atento a que el Proyecto PRC no continúa en ejecución y que la empresa promotora incumplió parcialmente los aportes comprometidos, entiende oportuno y conveniente dar por extinguido el contrato en razón del cumplimiento del plazo contractual.

\subsection{Tensiones por la Ley provincial de Minería 7722}

Asimismo, la caída del proyecto PRC con la consecuente pérdida de puestos de trabajo se convirtió en la razón principalpor la que la Cámara Mendocina de Empresarios Mineros (CAMEM) insistiese con su objetivo de declarar inconstitucional la Ley provincial de Minería 7722, "el gran impedimento para que las iniciativas de megaminería utilicen elementos químicos en sus actividades extractivas"12 . La meta de la CAMEM era reactivar varios de los emprendimientos paralizados por dicha ley, que además son fuertemente rechazados por la ciudadanía, como el caso de Sierra Pintada en San Rafael, Don Sixto en Malargüe o San Jorge en Uspallata.

En abril de 2017 la Suprema Corte de Justicia de Mendoza ratificó la decisión que había tomado en 2015 al rechazar un planteo de inconstitucionalidad hecho por cinco empresas mineras. La ratificación de la Ley 7722 se da en un contexto en el que el Ejecutivo aún analiza qué política minera llevar adelante.

Muy extensa ha sido la discusión por la minería, particularmente en Mendoza. El actual gobierno reactivó una Mesa de Diálogo Minero compuesta por el estado, empresarios, gremios y distintas organizaciones sociales con el objetivo de escuchar las opiniones de todos los actores involucrados para conformar una política de estado para una minería sustentable. Entre tanto, grupos ambientalistas piden declarar como reserva natural a zonas donde antes se proyectaban inversiones mineras.

\subsection{Reactivación del proyecto PRC}

A fines de 2016 Vale retoma el estudio de factibilidad del megaproyecto con miras a plantear una reestructuración del diseño original a un tercio de su capacidad y así volver el plan atractivo para la búsqueda de nuevos socios comerciales. El estudio fue llevado a cabo por la consultora canadiense Hatch que ajustó el proyecto original de la mina mediante la reducción de su capacidad de producción de 4 millones de toneladas al año a 1,4 millones.

Las variables económicas más importantes que elevan el valor del emprendimiento son la energía eléctrica, el gas y el transporte. En este sentido, el gobierno mendocino realizó a la minera una serie de propuestas alternativas en cuanto a la infraestructura energética planteando dos recursos estratégicos para reducir las inversiones en bienes de capital. En primer lugar se analizaría la provisión de tarifas de energía y gas competitivas para el proyecto mediante el desarrollo de nuevos pozos gasíferos. En segundo término, se ofrecería a oficiar de mediador para que la mina pueda compartir los costos de las obras eléctricas con otras actividades productivas de la región a través de la instalación, en la línea de alta tensión Comahue-Cuyo, de la subestación eléctrica en el paraje El Cortaderal (Malargüe).

12 Pese a que como se señaló anteriormente, PRC no entra dentro de la prohibición de la Ley 7722 porque utiliza agua caliente en el proceso extractivo. 
En 2017, la multinacional estadounidense Mosaic Company ${ }^{13}$ anunció la compra de la división de fertilizantes de Vale y evaluó la reactivación del proyecto con los resultados del estudio de factibilidad y mediante una reunión sostenida con funcionarios mendocinos y representantes de Vale. Sin embargo, Mosaic optó por no comprar el proyecto de potasio de Río Colorado en Argentina ante su complejidad logística y costos de transporte y energía.

En 2018, en pos de resolver el problema de logística y transporte del emprendimiento y así contribuir a su reactivación, el gobierno mendocino firmó un convenio con la empresa YPF para evaluar el desarrollo de una traza ferroviaria que una la mina con el océano atlántico. Son 150 kilómetros que vincularían a las localidades de Pata Mora con Añelo, provincia del Neuquén. A su vez, YPF y el Ministerio de Transporte de la Nación se encontrarían trabajando en el proyecto de 100 kilómetros que unirían a la localidad neuquina con Chinchinales, en Río Negro, para su posterior empalme con la ferrovía que la une al puerto de Bahía Blanca.

\section{Conclusiones}

Son innumerables los productos esenciales para la vida moderna que utilizan total o parcialmente sustancias de origen mineral. Empero, la minería a gran escala en Argentina se encuentra condicionada, entre otros factores, por la falta de infraestructura básica (energía eléctrica, gas, transporte, entre otros), siendo el proyecto PRC un ejemplo de dichos condicionantes, en particular por el enorme consumo de gas que requeriría el proyecto.

Asimismo, como se analizó, la megaminería es cada vez más seriamente cuestionada por sectores ambientalistas, académicos y por las poblaciones que habitan las zonas cercanas a las explotaciones. En este sentido, se observa en el caso considerado, el potencial riesgo de salinización del río Colorado, una de las cuencas más importantes de Argentina.

Al analizar el proyecto PRC se evidencian que temas claves como los modelos de desarrollo y ordenamiento territorial, el fortalecimiento de los mecanismos de control ambiental, la creación, distribución y transparencia de la renta minera, la participación y consentimiento previo de las comunidades locales y el acceso a la información legítima, deberían formar parte de una agenda común de diálogo donde se puedan expresar diferentes visiones, incluso contrapuestas, en un marco de respeto y participación plural, democrática e inclusiva.

El Estado suele brindar mayor atención a la promoción de la inversión minera privada que a la regulación y control de la actividad, como se puede observar en el proyecto PRC. Esto en la práctica podría denotar mayor acercamiento a los intereses de las empresas mineras que a los de las comunidades locales. Por ello se remarca la importancia de promover espacios de diálogo, debate y reflexión en torno a los desafíos que presentan los conflictos asociados al desarrollo de la actividad minera 13 The Mosaic Company es el mayor productor estadounidense de fertilizantes potásicos y fosfatados. Pertenece al Fortune 500 (lista anual compilada y publicada por la revista Fortune que clasifica a las 500 corporaciones más grandes de Estados Unidos por los ingresos totales para sus respectivos años fiscales). Con sede en Plymouth, Minnesota, Mosaic explota dos nutrientes clave para los cultivos: fosfato y potasio, produciendo derivados especializados. 
a gran escala en el país, buscando la diversidad en la participación.

En definitiva, cualquier estrategia de intervención productiva debería orientarse a la generación, recomposición y mejoramiento de la trama productiva local y a su integración dinámica a las cadenas de valor, de modo que se produzca un incremento en los ingresos y de las oportunidades de trabajo genuino. En el caso particular de PRC, al ser la minería una actividad que explota un recurso no renovable, ha de estar acompañada de herramientas que permitan el desarrollo integral de la región en todos sus aspectos.

Todo ello sin descuidar el compromiso que este tipo de decisiones representan para las próximas generaciones, en pos de un desarrollo de la actividad minera económico, ambiental y socialmente sustentable. La creciente inversión minera en Argentina podría representar un potencial importante para la sociedad en su conjunto y proyectos desarrollados y gestionados apropiadamente podrían llegar a constituir una oportunidad para promover el desarrollo sustentable en las comunidades locales.

\section{Referencias bibliográficas}

Aranda, D. (2015). Tierra arrasada: Petróleo, soja, pasteras y megaminería. Radiografía de la Petróleo, soja, pasteras y megaminería. Radiografía de la Argentina del Siglo XXI. Con crónicas y entrevistas de la Argentina profunda. Buenos Aires, Argentina: Sudamericana.

Arias Arce, V., Lovera Dávila, D., Puente Santibañez, L. y Calderón Celis, M. (2009). Contexto de la responsabilidad social minera y la gobernabilidad. Revista del Instituto de Investigaciones FIGMMG, 12 (23), 60-67.

Colectivo Voces de Alerta (2011). 15 Mitos y realidades de la minería transnacional en la Argentina. Guía para desmontar el imaginario prominero. Buenos Aires, Argentina: El Colectivo.

Comisión Europea (2011). Estrategia Renovada de la UE para 2011-2014 sobre la responsabilidad social de las empresas. Bruselas, Belgica: UE. Recuperado de https://eurlex.europa.eu/LexUriServ/LexUriServ.do?uri=COM:2011:0681: FIN:ES:PDF

Giuliani, A. (2013). Gas y Petróleo en la Economía de Neuquén. Neuquén, Argentina: Educo.

Gómez, R. y Baudino, M. C. (2008). Informe general del proyecto Potasio Río Colorado y sus implicancias ambientales en provincias de la República Argentina. Recuperado de http://cecades2008.activo.mx/t13-informegeneral-del-proyecto-potasio-rio-colorado-y-sus-implicancias-ambientalesen-provincias-de-la-republica-argentina

Gudynas, E. (2009). Diez tesis urgentes sobre el nuevo extractivismo. Contextos y demandas bajo el progresismo sudamericano actual. En J. Schuldt, A. Acosta, A. Barandiarán, A. Bebbington, M. Folchi, CEDLA-Bolivia, A. Alayza y E. Gudynas, Extractivismo, política y sociedad (187-225). Quito, Ecuador: 
Centro Andino de Acción Popular (CAAP) y Centro Latino Americano de Ecología Social (CLAES).

Hollmann, M. A. y Giuliani, A. (2011). Fondo fiduciario de Administración Responsabilidad Social Empresaria - Ley 2.615 Provincia del Neuquén. II Jornadas Patagónicas de Investigación en Ciencias Económicas. Comodoro Rivadavia, Argentina.

Hollmann, M. A. (2015). El modelo productivo dominante y la responsabilidad social. En M. Cardone (Coord.), Desarrollo territorial en la provincia de Neuquén: energía, forestación y turismo (17-46). Neuquén, Argentina: EDUCO.

KPMG. (2018). Algunos temas relevantes para la minería en 2018. Recuperado de https://assets.kpmg.com/content/dam/kpmg/ar/pdf/informe-especialmineria-argentina-2018.pdf

Licha, I. (Comp.). (2012). Enfoque y Herramientas de Formación en Responsabilidad Social Empresarial en Iberoamérica. Nueva York, EEUU : PNUD.

Morrós Ribera, J. y Vidal Martínez, I. (2005). La Responsabilidad Social Corporativa. Madrid, España: Fundación Confemetal.

Potasio Río Colorado. (2008). Resumen ejecutivo del informe de impacto ambiental del proyecto Potasio Río Colorado.

Svampa, M. y Viale, E. (2014). La Argentina del extractivismo y el despojo. Buenos Aires, Argentina: Katz editores.

Svampa, M. (2016). Debates latinoamericanos. Buenos Aires, Argentina: Edhasa.

Veltmeyer, H. y Petras J. (2015). El neoextractivismo. México, México: Grupo Planeta.

\section{Legislación}

Poder Ejecutivo de la Nación Argentina. (2008). Decreto 2019/2008. Buenos Aires, Argentina: Poder Ejecutivo de la Nación.

Poder Ejecutivo de la Nación Argentina. (2012). Decreto 1299/2012. Buenos Aires, Argentina: Poder Ejecutivo de la Nación.

Poder Ejecutivo de la Provincia de Río Negro. (2012). Decreto 228/2012. Viedma, Argentina: Poder Ejecutivo de Río Negro.

Poder Ejecutivo de la Provincia del Neuquén. (2011). Decreto 1519/2011.Neuquén, Argentina: Poder Ejecutivo de Neuquén.

Poder Ejecutivo de la Provincia del Neuquén. (2013). Decreto 739/2013. Neuquén, Argentina: Poder Ejecutivo de la Provincia del Neuquén.

Poder Legislativo de la Nación Argentina. (2002). Ley General del Ambiente 25675. Buenos Aires, Argentina: Poder Legislativo de la Nación Argentina. 
Poder Legislativo de la Provincia de Mendoza. (1992). Ley 5961. Mendoza, Argentina: Poder Legislativo de la Provincia de Mendoza.

Poder Legislativo de la Provincia de Mendoza. (2007). Ley 7722. Mendoza, Argentina: Poder Legislativo de la Provincia de Mendoza.

Poder Legislativo de la Provincia de Neuquén. (2010). Ley 2755. Neuquén, Argentina: Poder Legislativo de la Provincia de Neuquén. 